\title{
SERUM LIPOIDS IN DIABETES
}

\author{
By EVELYN B. MAN AND JOHN P. PETERS \\ (From the Departments of Internal Medicine and of Psychiatry, Yale University School of \\ Medicine, and the Medical Service of the New Haven Hospital, New Haven)
}

(Received for publication June 4, 1935)

Recently high-carbohydrate, low-fat diets have been widely advocated for diabetic patients ( 3 , $17,20,23,24,30,36,48,52)$. As arguments for this therapy it has been claimed that hypercholesterolemia is of grave prognosis in diabetes and that high fat diets may superinduce hyperlipemia. The following investigation was undertaken to determine the incidence of hypercholesterolemia in diabetes, to study the relation of the cholesterol level to that of fatty acids and phospholipoids in blood serum, and also to learn whether diets moderately high in fat such as are used in this clinic give rise to hyperlipemia.

\section{MATERIALS AND METHODS}

The serum, from venous blood taken before the morning insulin or breakfast, of 79 different diabetic patients, 20 males and 59 females of all ages, has been examined 130 times for cholesterol, lipoid phosphorus and non-phospholipoid fatty acids by methods already described $(37,38)$. The percentage errors of the analytical techniques have been discussed previously $(37,38,40)$. In almost every instance serum proteins (11) and blood sugar $(4,54)$ were determined simultaneously. No studies which were made when the patients were dehydrated, acidotic, pregnant, postpartum, or had been treated with intravenous injections of acacia are included.

\section{DATA}

Data are given in Table I. Insulin dosage and protein, fat and carbohydrate intake indicate the requirements and food consumption of the patient for at least four or five days previous to the blood study. Whenever there was any doubt that the diet had been followed adequately, the term " unregulated" has been used. The blood of many of these patients was examined the morning after admission to the hospital, and unless there was an exact record of the diet the regimen was condemned to the " unregulated" category. Brief protocols concerning each patient are presented at the end of the paper. Notes are included where there were evidences of hypertension or arteriosclerosis, the latter being judged by evidences of sclerosis in the eyegrounds and extremities, cardiac enlargement and decompensation. Blood pressures were observed on all patients, not always on the day of the blood study, but when the subject was neither unduly excited nor in circulatory embarrassment. In addition to the actual body weight, the impression of nutritional state is described. Any evidences of liver pathology or enlargement, or of kidney pathology, are included, but neither organ is mentioned unless an abnormality was discovered. The albumin and globulin in the serum of more than half the patients were determined. In most instances any alteration in total protein was due to a variation in albumin, but in certain cases when the albumin:globulin ratio was abnormal the concentrations of the fractions are included.

Cases have been grouped according to the concentration of cholesterol in the serum. Whenever this fluctuated the study used for classification was selected when the condition of the patient was most nearly normal or when the cholesterolemia had attained a constant level. The table includes first the patients who exhibited hypercholesterolemia, secondly those with hypocholesterolemia and lastly those with normal cholesterolemia. The first subdivision of the hypercholesterolemia group includes subjects with greatly elevated cholesterols or with flagrant complications; and the second group, those relatively uncomplicated diabetics whose serum cholesterols were between 250 and 304 milligrams per cent. An attempt has been made to arrange the subjects so that those with similar complications are listed together. In the group with normal cholesterolemia the first thirteen patients had no evident complications. 
TABLE I

\begin{tabular}{|c|c|c|c|c|c|c|c|c|c|c|c|}
\hline \multirow[b]{2}{*}{$\begin{array}{c}\text { Case } \\
\text { number }\end{array}$} & \multirow[b]{2}{*}{ Date } & \multicolumn{5}{|c|}{ Serum } & \multirow[b]{2}{*}{$\begin{array}{l}\text { Blood } \\
\text { sugar }\end{array}$} & \multirow[b]{2}{*}{$\underset{\text { sulin }}{\text { In- }}$} & \multicolumn{3}{|c|}{ Diet } \\
\hline & & Cholesterol & $\begin{array}{c}\text { Lipoid } \\
\text { phos- } \\
\text { phorus }\end{array}$ & $\begin{array}{l}\text { Non- } \\
\text { phospho- } \\
\text { lipoid } \\
\text { fatty } \\
\text { acids }\end{array}$ & $\begin{array}{l}\text { Total } \\
\text { fatty } \\
\text { acids }\end{array}$ & Protein & & & Protein & Fat & $\begin{array}{l}\text { Car- } \\
\text { bohy- } \\
\text { drate }\end{array}$ \\
\hline & & $\begin{array}{c}\text { mgm. per } \\
100 \text { cc. }\end{array}$ & $\begin{array}{c}\text { mgm. per } \\
100 \text { cc. }\end{array}$ & m. eq. & m. eq. & per cent & $\begin{array}{c}\text { mgm. per } \\
100 \text { cc. }\end{array}$ & units & grams & grams & grams \\
\hline
\end{tabular}

A. HYPERCHOLESTEROLEMIA

1. Severe hypercholesterolemia and patients with severe complications

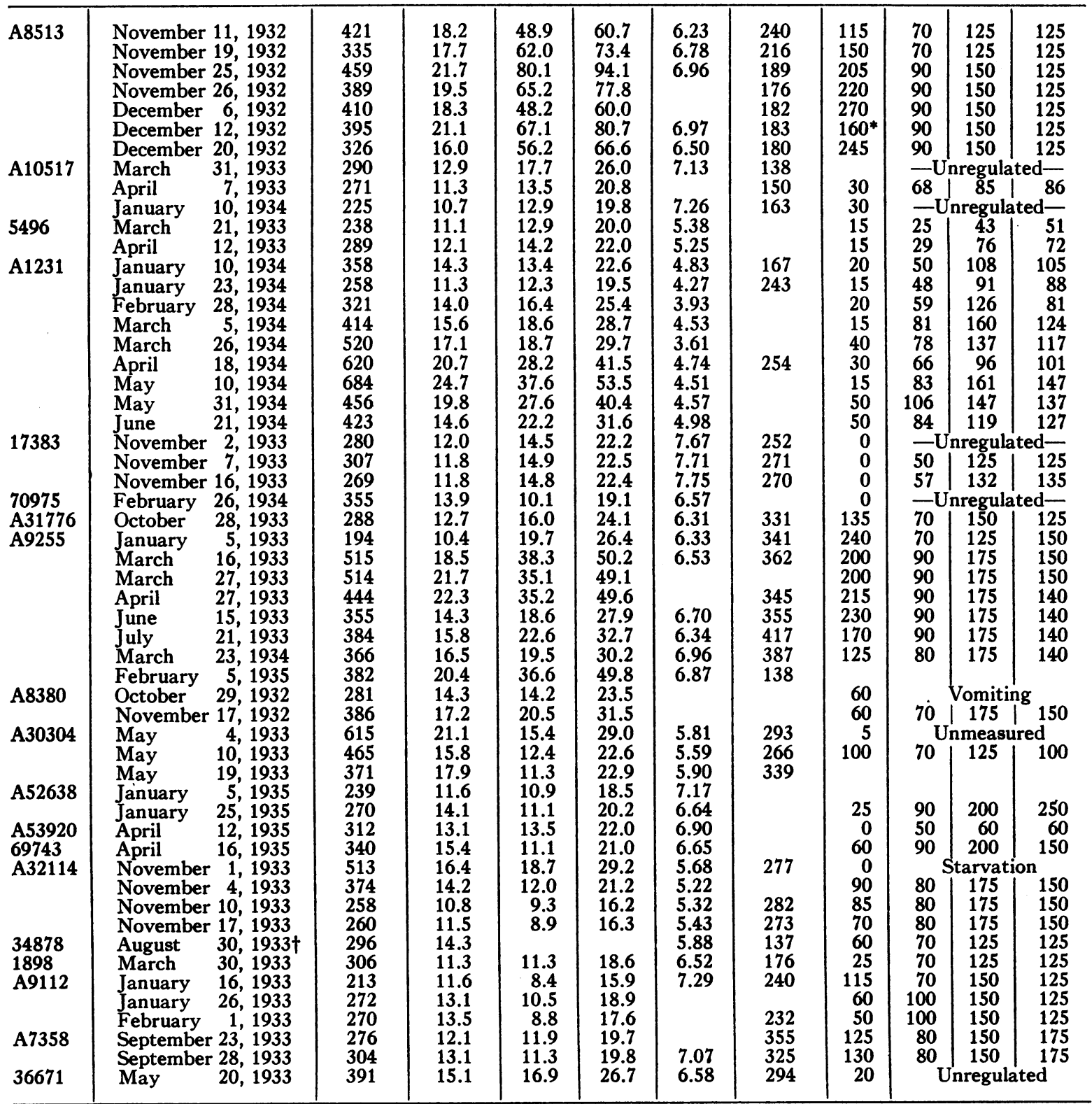

* Beef insulin.

$\dagger 3$ P.M. 
TABLE I-Continued

\begin{tabular}{|c|c|c|c|c|c|c|c|c|c|c|c|}
\hline \multirow[b]{2}{*}{$\begin{array}{c}\text { Case } \\
\text { number }\end{array}$} & \multirow[b]{2}{*}{ Date } & \multicolumn{5}{|c|}{ Serum } & \multirow[b]{2}{*}{$\begin{array}{l}\text { Blood } \\
\text { sugar }\end{array}$} & \multirow[b]{2}{*}{$\begin{array}{l}\text { In- } \\
\text { sulin }\end{array}$} & \multicolumn{3}{|c|}{ Diet } \\
\hline & & Cholesterol & $\begin{array}{l}\text { Lipoid } \\
\text { phos- } \\
\text { phorus }\end{array}$ & $\begin{array}{l}\text { Non- } \\
\text { phospho- } \\
\text { lipoid } \\
\text { fatty } \\
\text { acids }\end{array}$ & $\begin{array}{l}\text { Total } \\
\text { fatty } \\
\text { acids }\end{array}$ & Protein & & & Protein & Fat & $\begin{array}{l}\text { Car- } \\
\text { bohy- } \\
\text { drate }\end{array}$ \\
\hline & & $\begin{array}{c}\text { mgm. per } \\
100 \text { cc. }\end{array}$ & $\begin{array}{l}\text { mgm. per } \\
100 \text { cc. }\end{array}$ & m. eq. & m. eq. & per cent & $\begin{array}{c}\text { mgm. per } \\
100 \text { cc. }\end{array}$ & units & grams & grams & grams \\
\hline
\end{tabular}

2. Mild hypercholesterolemia

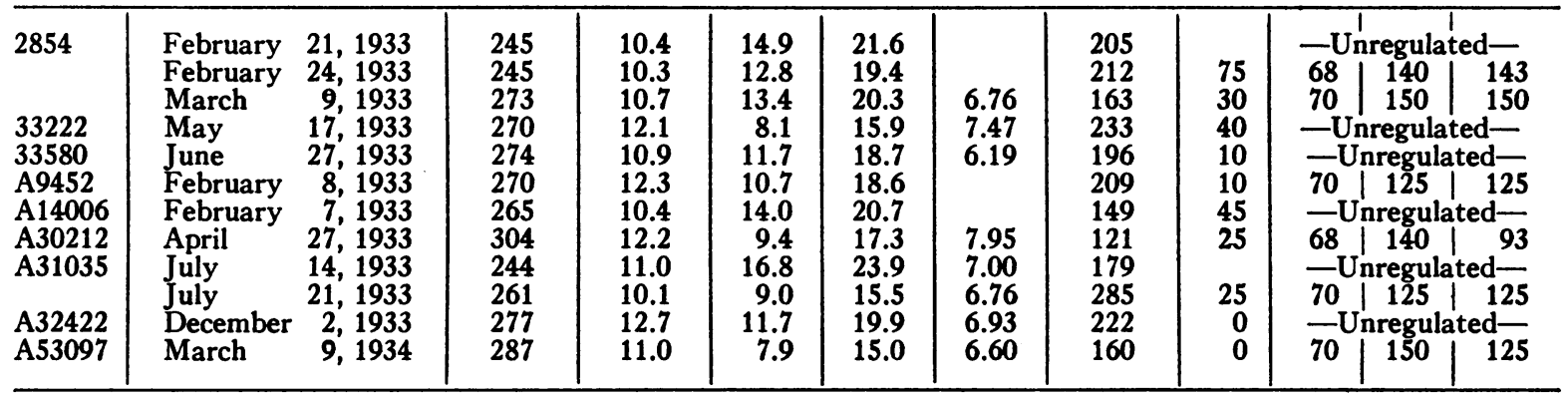

B. HYPOCHOLESTEROLEMIA

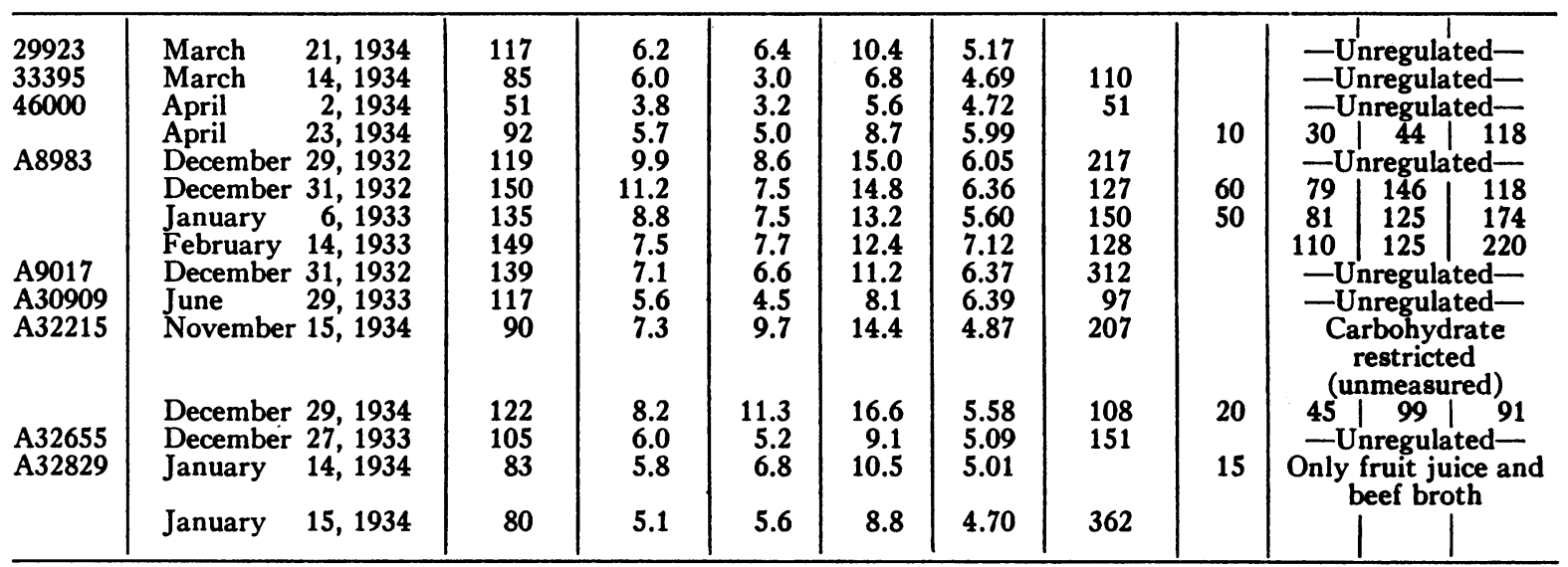

C. NORMAL CHOLESTEROLEMIA

1. Uncomplicated diabetics

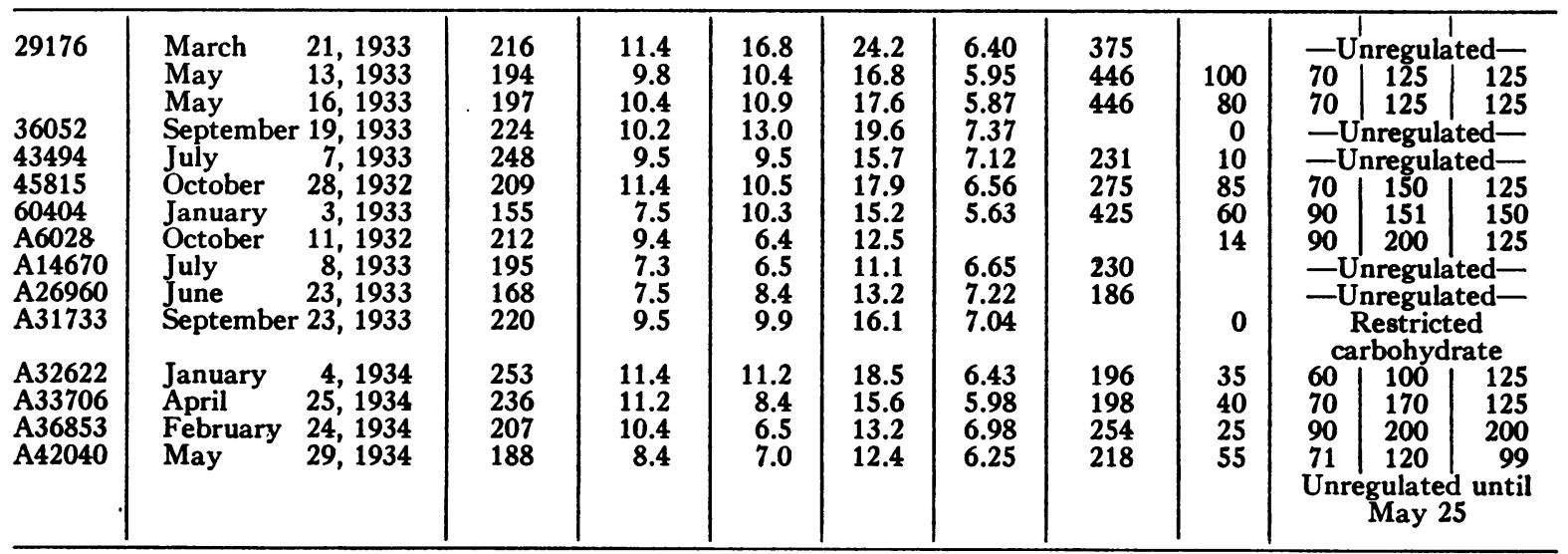


TABLE I-Continued

\begin{tabular}{|c|c|c|c|c|c|c|c|c|c|c|c|}
\hline \multirow[b]{2}{*}{$\begin{array}{c}\text { Case } \\
\text { number }\end{array}$} & \multirow[b]{2}{*}{ Date } & \multicolumn{5}{|c|}{ Serum } & \multirow[b]{2}{*}{$\begin{array}{l}\text { Blood } \\
\text { sugar }\end{array}$} & \multirow[b]{2}{*}{$\begin{array}{l}\text { In- } \\
\text { sulin }\end{array}$} & \multicolumn{3}{|c|}{ Diet } \\
\hline & & Cholesterol & $\begin{array}{c}\text { Lipoid } \\
\text { phos- } \\
\text { phorus }\end{array}$ & $\begin{array}{l}\text { Non- } \\
\text { phospho- } \\
\text { lipoid } \\
\text { fatty } \\
\text { acids }\end{array}$ & $\begin{array}{l}\text { Total } \\
\text { fatty } \\
\text { acids }\end{array}$ & Protein & & & Protein & Fat & $\begin{array}{l}\text { Car- } \\
\text { bohy- } \\
\text { drate }\end{array}$ \\
\hline & & $\underset{100}{\text { mgm. per }}$ cc. & $\begin{array}{c}\text { mgm. per } \\
100 \text { cc. }\end{array}$ & m. eq. & m. eq. & per cent & $\begin{array}{c}\text { mgm. per } \\
100 \text { cc. }\end{array}$ & units & grams & grams & grams \\
\hline
\end{tabular}

2. Complicated diabetics

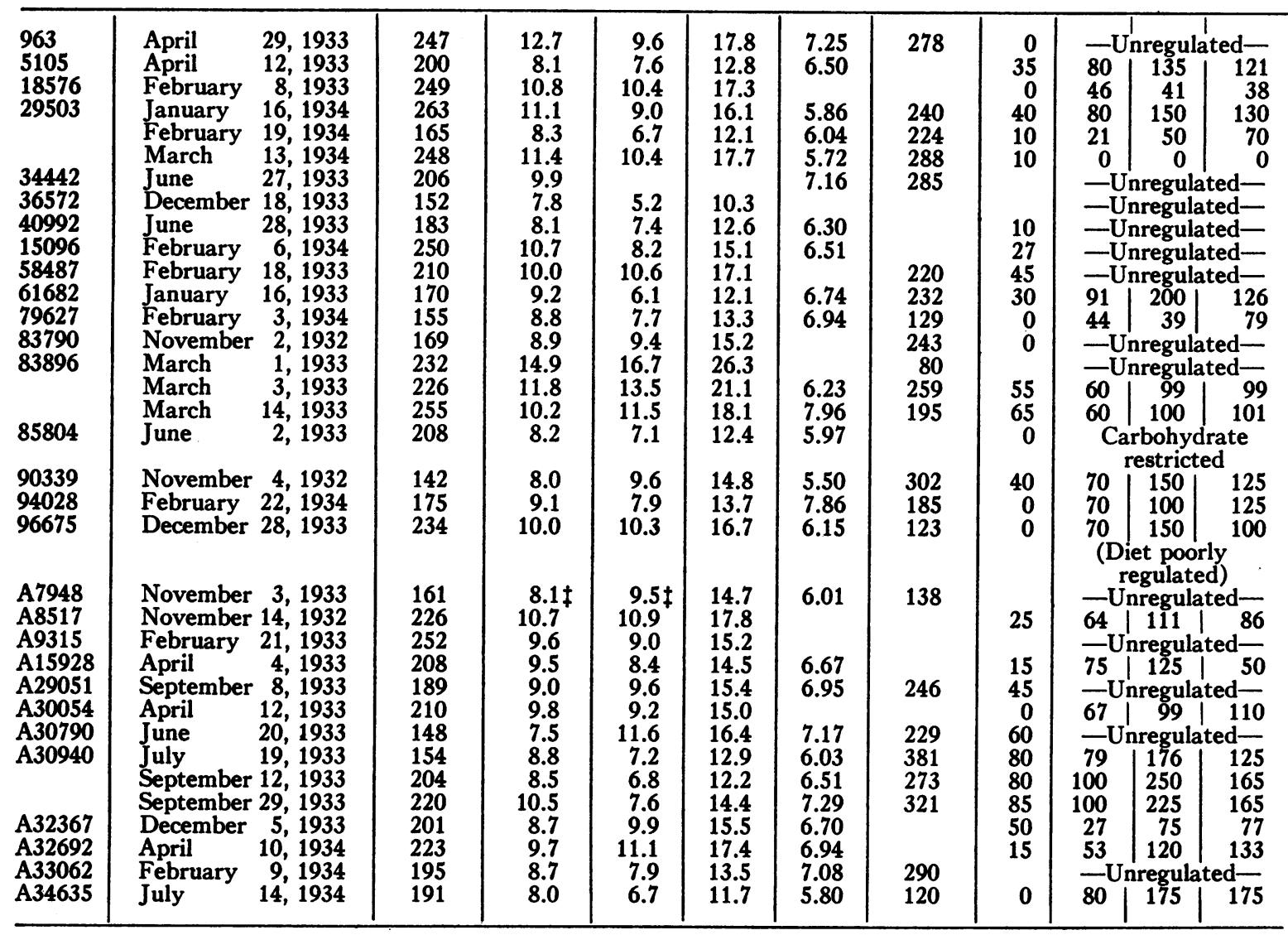

$\ddagger$ One determination.

In Figures 1 and 2, cholesterol is compared with non-phospholipoid fatty acids and with lipoid phosphorus respectively. Only one determination from each of the seventy-nine patients has been included. Whenever a long series of studies has been made the final determination has been selected because most patients were best regulated at the time of the last study. The range of normal values is indicated on each chart by an enclosed area.

\section{OBSERVATIONS}

\section{Infrequency of hypercholesterolemia in diabetes}

Of the 79 patients, serum cholesterol was normal in 42 , above normal in 28 , and below normal in 9. The normal range for serum cholesterol is considered to be 150 to 256 milligrams per cent (38), although at present an attempt is being made to ascertain whether the range for females is the same as that for males. Such an analysis 


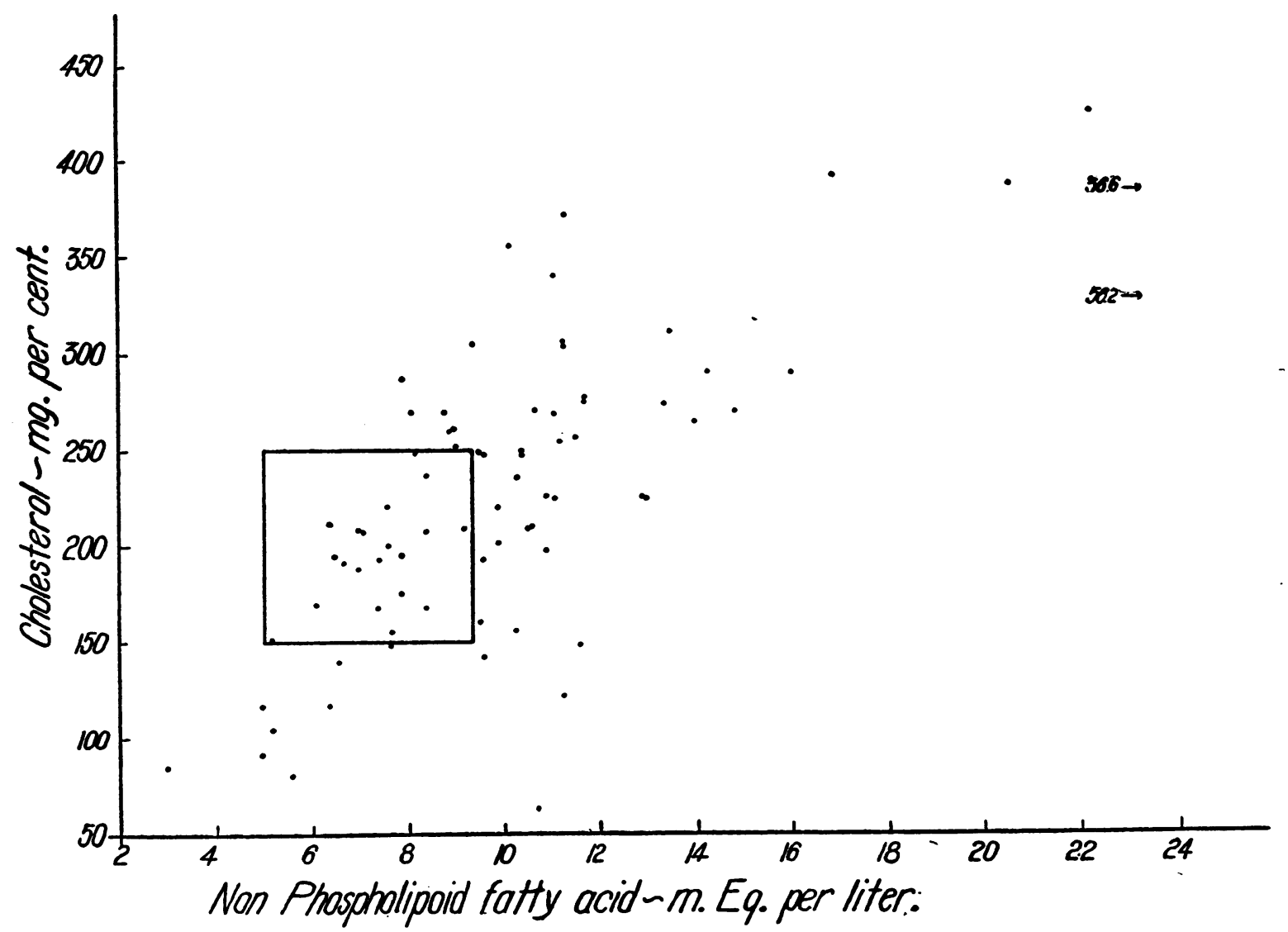

Fig. 1. Relation Between Cholesterol and Non-phospholipoid fatty Acids of Serum.

Only the last determination from each subject is given. The square defines the limits of normal variation.

shows that hypercholesterolemia in diabetes is less frequent than is generally supposed. Of the 28 patients with hypercholesterolemia all were females, except two (A8513, A10517) with liver cirrhosis, one (70975) with nephrosis, and one (A53920) with vasomotor instability, even though about 27 per cent of the patients studied were men.

Of the first nineteen patients who had hypercholesterolemia of considerable severity, all but three had complications which may have been largely or entirely responsible for the lipoid disturbance. Two (A8512 and A10517) were suffering from cirrhosis, which is notoriously associated with disorders of cholesterol metabolism $(18,55)$. Four $(5496,17383,70975$, A1231) had severe kidney disease, the two last with frankly nephrotic aspects. A31776, at the time of the recorded observations, had a generalized xanthomatous eruption. The next seven cases make up a rather peculiar group. The first, A9255, had acromegalic diabetes with extreme symptoms of autonomic instability, suggesting involvement of the hypothalamus: nervousness, flushing, excessive sweating and tachycardia. In addition, her basal metabolism was greatly increased and remained elevated after subtotal thyroidectomy. A32114, A30304, A8380, A52638, A53920 and 69743 exhibited similar symptoms and signs of sympathetic irritability without definite stigmata of pituitary disease. The basal metabolisms of the last five were also increased, and that of A52638 failed to respond adequately to thyroidectomy, until five weeks after the last determination of blood lipoids which had been made ten days after the second operation of a two-stage thyroidectomy. A32114 had subsisted for some time on an extremely limited diet. Since the hypercholesterolemia subsided within nine days under treatment, it may have been connected with 


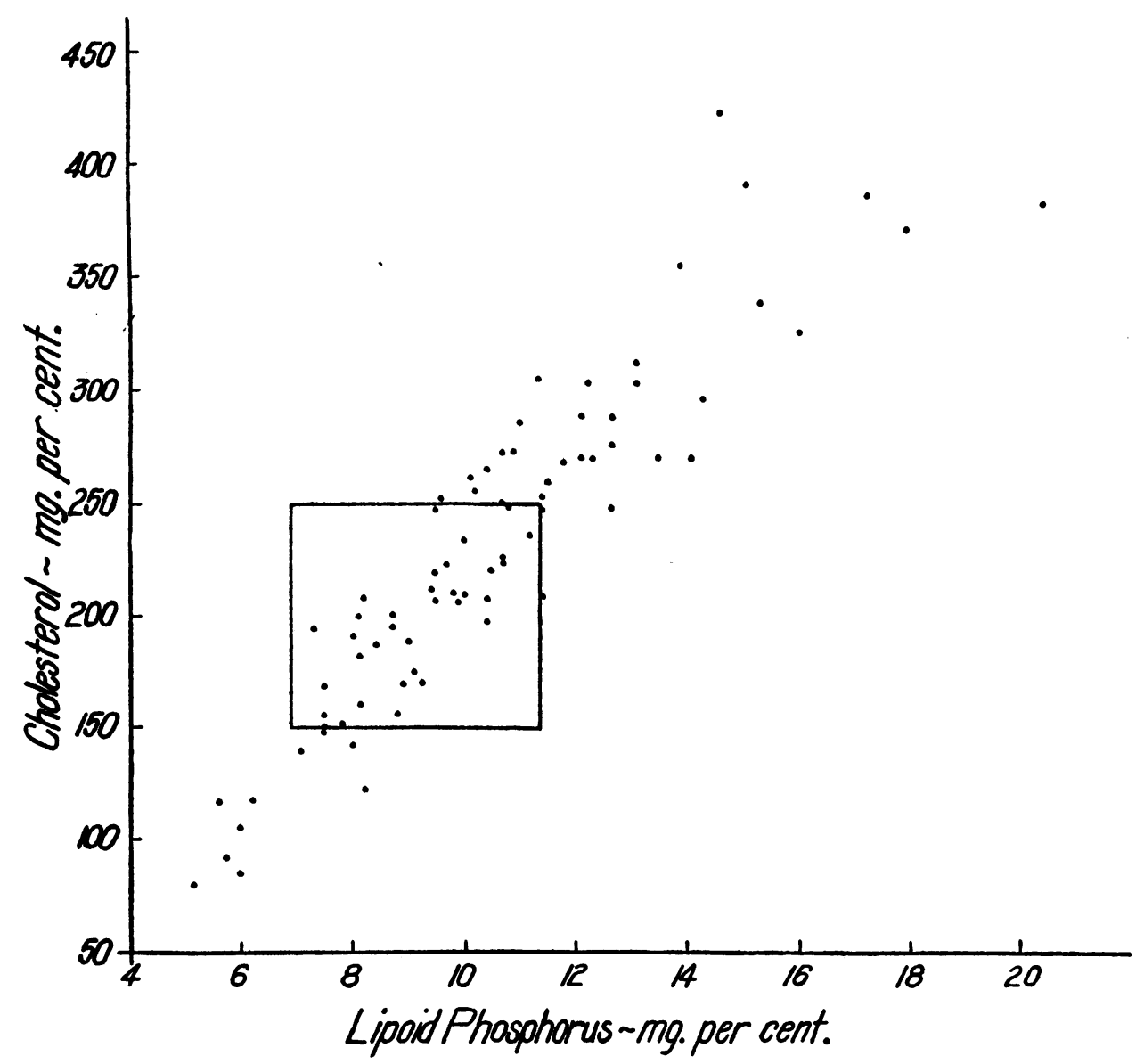

Fig. 2. Relation Between Cholesterol and Lipoid Phosphorus.

Only the last determination from each subject is given. The square defines the limits of normal variation.

some acute disturbance of undiscovered nature. The patient had shown large amounts of acetone in the urine $(2+$ to $4+)$ for the two days after admission to the hospital and prior to the initial blood study. Of the next two patients, 34878 had Parkinson's disease, while 1898 had diabetes insipidus.

For the hypercholesterolemia in the three remaining cases of the first group no distinct complications can be held responsible. A9112 had pernicious anemia and vague symptoms of vasomotor instability, such as slight tachycardia and unstable carbohydrate metabolism. A7358, a child of 13, was studied after recovery from severe acidosis, which had been precipitated by an acute exacerbation of a chronic purulent otitis media.
Most of the nine patients, all females, in the next group with moderate hypercholesterolemia presented minor complications : cataracts, retinitis, cholelithiasis, infections, etc. 2854 might easily be included in the normal group, but as her cholesterol rose with improvement from 245 to 273 milligrams per cent, the latter was selected as the fairest criterion of her " normal" cholesterolemia. All the patients in this group were frankly overweight or somewhat overnourished.

\section{Hypocholesterolemia}

A8983, one of the 9 patients with hypocholesterolemia, had hypertrophic cirrhosis of the liver and should be omitted from the series because cirrhosis may, according to Epstein (18) and Thannhauser and Schaber (55), cause either 
elevation or diminution of cholesterolemia. This leaves eight patients with striking hypocholesterolemia. All were markedly emaciated or malnourished, often with low serum albumin and massive edema, like that of A32215 who had been on a fluid diet for six days following an appendectomy complicated by peritonitis.

\section{Cholesterolemia as a criterion of lipemia}

In Figure 1 cholesterols have been charted against non-phospholipoid fatty acids. Immediately it is apparent that the fatty acids may be distinctly above the normal maximum, even when the cholesterol is not. The number of cases in which this occurs is much greater than the number of cases in which a hypernormal cholesterol is associated with fatty acids within the normal range. Also the fatty acids may be within the normal range when the cholesterolemia is below normal, although normal cholesterol has not been found with subnormal fatty acids. The independence of variations in cholesterol and fatty acids has already been discussed in a previous article on diabetic acidosis (40) and is in contrast to the findings of certain other investigators $(7,9,15$, $27,46,47,59$ ).

That the concentrations of cholesterol and lipoid phosphorus in blood serum bear a distinct relation to each other is clearly demonstrated in Figure 2. This has already been suggested by Bloor (8). A graphic comparison of cholesterol and total fatty acids shows only lack of correlation, like that between cholesterol and non-phospholipoid fatty acids. This might easily be deduced from a study of Figures 1 and 2. Similarly it may be argued from these same figures that lipoid phosphorus and non-phospholipoid fatty acids may vary independently.

\section{DISCUSSION}

The statistical correlation between lipoid phosphorus and cholesterol in blood serum is quite close. Although the correlation between serum cholesterol and fatty acids is far less regular, there is a general tendency to correlation, which is evidenced in the fact that no markedly elevated fatty acids were found in the groups with cholesterol normal or below normal, and that fatty acids were consistently above normal in those with marked hypercholesterolemia. For these reasons generalizations in this discussion in regard to cholesterolemia and phospholipoidemia are applicable also to lipemia. No attention has been given to ratios of lipoid constituents because of the uncertainty concerning the functional relationship of the various fractions. It is not surprising in light of the differences in constitution and properties of fatty acids and cholesterol, that in spite of the general correlation between these two substances independent variations are observed. Such dissimilar substances must be metabolized by different processes. For example, a marked increase in serum fatty acids after the ingestion of food is not accompanied by a rise in serum cholesterol $(2,5,6,7,13,14,19,26,33,41)$. Similarly, the increase in fatty acids in diabetic acidosis far exceeds the elevation of cholesterol (40). In Figure 1, in which cholesterol and non-phospholipoid fatty acids are compared, the lack of correlation is partially masked because the non-phospholipoid fatty acids have not been corrected for the fraction combined with cholesterol. In the cholesterol esters about seventy per cent of the cholesterol $(10,18,35,45,55)$ and about half the nonphospholipoid fatty acids are chemically combined.

Our data show that hypercholesterolemia of uncomplicated diabetics did not exceed 304 milligrams per cent, and also that cholesterols between 250 and 304 milligrams per cent were only encountered in 9 of 79 diabetics. The explanation for the low incidence of hypercholesterolemia undoubtedly depends on the fact that there have been omitted from this series all diabetics with dehydration or acidosis. The justification for such omissions rests upon a previous investigation, in which it was demonstrated that dehydration was largely responsible for the hypercholesterolemia of diabetic acidosis (40). It has been shown that the capillaries are impermeable to both serum proteins and cholesterol (39) and that hemoconcentration causes the concentration of both these constituents to increase. For example, the alleviation of dehydration of one acidotic patient (90339), when the serum proteins fell from 7.92 to 4.87 per cent, would account for a diminution of serum cholesterol from 275 to 169 milligrams per cent (40). The relation of lipoids to proteins of serum, and consequently to blood volume, in patients without diabetic acidosis has already been considered $(39,40)$. In this series, no pa- 
tient has been included who showed clinical symptoms of dehydration or who immediately after hospitalization had a limited urine output in relation to fluid intake. Such dehydrated patients may have been included in earlier studies of diabetic cholesterolemia. Insufficient attention may also have been given to the complications which so commonly accompany diabetes.

Especial virtue has been ascribed to the determination of serum cholesterol as a measure of the severity of diabetes. When patients with obvious acidosis are excluded, as they are in this series, there is no discoverable relation between serum cholesterol and the gravity of the disease, measured either in terms of insulin requirement or carbohydrate tolerance. Most of the patients with hypocholesterolemia were extremely ill and profoundly emaciated. As a group the patients with mild hypercholesterolemia did not require excessive amounts of insulin: the maximum requirement after regulation was $\mathbf{4 5}$ units daily, one (A53097) required no insulin, two (33580, A9452) required only 10 units of insulin daily, and two (A30212, A31035) 25 units; while in the group with normal cholesterols were 29176 taking 100 units of insulin daily, 45815 using 85 units of insulin, A30940 using 80 units, 83896 using 65 units and A42040 on 55 units.

It is quite as impossible to relate either cholesterolemia or lipemia to fat intake. Within the normal range were the fatty acids and cholesterol of 61682, A6028, A30940 and A36853, all of whom ate 200 grams of fat daily, of A33706 and A34635 who had 170 and 175 grams of fat respectively, and of 45815 and 90339 who had 150 grams of fat; while of the 9 patients with mild hypercholesterolemia, 2 had 150 grams of fat daily; 1, 140 grams; 2, 125 grams; and 4, unregulated amounts of fat. A32114, who had been on a starvation diet, has been mentioned previously. During ten days of a diet consisting of 80 grams of protein, 175 grams of fat and 150 grams of carbohydrate, her cholesterol fell from 513 to 259 milligrams per cent and her total fatty acids from 29.2 to 16.2 milli-equivalents. One week later, after continuance on the same diet, her lipoids were at precisely the same level. A30940, who entered the hospital in July, 1933, in a profoundly malnourished condition, went through a stormy course of pleurisy with effusion and staphylococcus abscesses of the areolar tissue. On July 12 , she was placed on a diet containing 175 grams of fat and 2400 calories, which was later increased to a diet containing 200 grams of fat, 90 of protein and 150 of carbohydrate. About September 12 this was changed to 250 grams of fat, 100 of protein and 165 of carbohydrate, and was reduced to 225 grams of fat before September 29 . As the malnutrition was alleviated, in spite of this high fat diet, the cholesterol rose only to 204 and 200 milligrams per cent on September 12 and 29, and the fatty acids only to 12.2 and 14.3 milliequivalents on these dates.

Among cases with rapidly changing diets the discrepancy between cholesterolemia and lipemia is most marked but is not related to the fat in the diet. Hyperlipemia of a mild degree occurred simultaneously with normal cholesterols in certain patients, 963, 18576, 29176, 29503, 36052, 58487, 83896 , who had been on an unregulated diet or who had abandoned a diabetic regimen. A31035 is an outstanding example of this, for before the initial study on July 14, 1933, diabetes had not been diagnosed and no limitations of diet had been prescribed. At this time her fatty acids were 23.9 milli-equivalents although they fell to 15.5 milliequivalents after seven days on 125 grams of fat and 1900 calories. During this interval the cholesterol did not follow the fatty acids but increased from 244 to 261 milligrams per cent.

The argument which has been advanced in behalf of high-carbohydrate, low-fat diets, that highfat diets tend to produce hypercholesterolemia, has not been substantiated by other investigators. Curtis, Sheldon and Eckstein (16) in a case of diabetes with xanthomatosis and lipemia retinalis noted a reduction in total blood lipoids from 1.780 per cent to 1.400 per cent on a diet of 55 grams of protein, 300 grams of fat and 270 grams of carbohydrate when sufficient insulin was administered to insure aglycosuria and normal blood sugar. Rabinowitch (49) reported 500 cases, the second 250 of which were treated with his new low-fat, high-carbohydrate diet. His data show that only 76 on the new diet, in contrast to 118 on the older. diet, had cholesterols ranging between 151 and 200 milligrams per cent and that only 31 of Group II, instead of 40 of Group I, had cho- 
lesterols between 200 and 250 milligrams per cent. Whether this reduction in cholesterolemia is important is questionable because many investigators have found that cholesterols of normal subjects vary within the limit of 150 to 250 milligrams per cent. Nevertheless, on this new high-carbohydrate, low-fat diet, 14 patients with cholesterolemia of 250 to 200 milligrams per cent were observed, while only 5 were noted in the group ingesting the older diet. Similarly 11 of Group II, in contrast to 6 of Group I, had serum cholesterols above 301 milligrams per cent. Bruger and Poindexter (12) have found that high-fat, high-calorie diets, productive of obesity, are not associated with increases in plasma cholesterol.

The tendency to obesity of the nine subjects with slightly elevated cholesterols must be considered as peculiar to the individual rather than as the result of a large fat intake. It seems probable that these cholesterols between 250 and 304 milligrams per cent are more closely related to the sex and body build $(22,51,59)$ than to the diabetic condition. Bruger and Poindexter, while studying cholesterolemia in relation to 94 patients who were more than twenty per cent overweight, had in their series only 4 males, but 90 females (12). This seems to indicate that an unusual lipoid metabolism, one manifestation of which is an elevation in serum cholesterol, may be associted with a particular form of obesity often observed in females.

Cachexia has long been thought to be accompanied by a low level of cholesterolemia. The finding that all of the patients with hypocholesterolemia were extremely emaciated and had low serum albumin indicates a distinct relation between nutrition and the level of serum cholesterol. To demonstrate the converse, that all emaciated patients have a low cholesterol, is more difficult because the degree of emaciation is hard to define and it is difficult to differentiate a person of lean build who has lost a little weight from a subject with more pronounced tissue wasting. For example, A33706, with a serum cholesterol of 236, was extremely thin but showed no muscular wasting. In spite of her undernourished appearance the serum albumin was 4.50 per cent, although it has already been shown that severe emaciation is attended by a diminution in serum albumin (44).
Again, 61682 was extremely thin but was of a spare physique and had a serum cholesterol of 170 milligrams per cent and an albumin of 4.14 per cent, both within the normal range. In the hypercholesterolemia group there are two patients (A30304, A32114) with profound emaciation who had cholesterols above normal when the wasting was most pronounced. Some unrecognized factor may here affect the cholesterolemia, just as some unrecognized factors produce hypercholesterolemia in nephrosis even when there is profound malnutrition.

On account of conflicting observations (1, 21, $31,32,34,43,50,53)$ in regard to cholesterolemia and arteriosclerosis, the clinical picture of every diabetic in Figure 1 was scrutinized to evaluate the degree of vascular degeneration. Lipoid values and blood pressure were also compared. It was found that severe arteriosclerosis, with or without hypertension, was evident in patients with serum cholesterols normal, below normal and above normal.

In all problems connected with diabetes a distinction must be drawn between those phenomena which are associated only with the disturbance of carbohydrate metabolism and those which are characteristic of the underlying disease. This is the more necessary since it has become evident that the pancreas alone need not be held responsible for all cases of diabetes. From this point of view the chief impression derived from this study is that abnormalities of serum lipoids are related loosely, if at all, to diabetes. Certainly hyperlipemia and hypercholesterolemia are not a regular part of the diabetic syndrome and, when they do occur, cannot be connected with the inherent severity of the disease, measured by any recognized criteria. In diabetic acidosis a relative or absolute hyperlipemia is regularly observed, which diminishes or disappears with the acidosis. It was pointed out in an earlier communication (40) that this hyperlipemia is largely, but not entirely, a product of hemoconcentration. During recovery, the reductions of the various lipoid fractions were not exactly proportional to one another nor to the fall of serum proteins. This suggested that these fractions were influenced in part, and to different degrees, by something other than hemoconcentration. In general, the relative magnitudes of 
the reductions took the following order: nonphospholipid fatty acids $>$ phospholipids $>$ cholesterol $>$ protein. This is the order of importance conventionally ascribed to these components in fat metabolism. The increases in excess of the effects of hemoconcentration may, then, represent merely the mobilization of fat to meet an emergency demand in a condition in which utilization of carbohydrate is reduced to a minimum, if not abolished.

The patients considered in this paper were studied in conditions in which, although carbohydrate tolerance was impaired, they were utilizing sugar. To be sure the actual proportion of carbohydrate in the metabolic mixtures was less than that in the ordinary dietary of normal persons. But this would seem to have had little influence upon lipemia, since this cannot be correlated with diet in any respect. The amount of carbohydrate presumably burned was no greater among those with hypolipemia than among the hyperlipemic. In treated diabetics, then, it would seem necessary to seek the causes of disturbances of lipemia in peculiar features of the individual patterns of the underlying disease. In a certain proportion, adequate explanations for hyperlipemia can be found in complications or associated diseases such as cirrhosis of the liver, nephrosis or other renal disorders.

When these are eliminated it is found that most of the remainder with greatly elevated lipoids fall into a group that presents one common feature, which may be roughly spoken of as instability of the autonomic nervous system. This is reflected also in instability of carbohydrate tolerance, which baffles regulation of insulin and diet. In this class belong particularly the 10 cases (A9255 to 1898 , inclusive). To define the syndrome further is impossible. The basal metabolism was frequently above normal. In some instances it failed to respond to iodine; in others it changed but little after thyroidectomy. But these were not common characteristics of all cases. For example, under iodine therapy the basal metabolism of A53920 fell from +30 to +16 per cent, suggesting simple hyperthyroidism. Nevertheless, in this case, as in all the others, most of the stigmata of hyperthyroidism were lacking. Moreover, the association of hyperlipemia with hyperthyroidism is strangely at variance with the claims of Hurxthal $(28,29)$ and others that serum cholesterol is regularly low in this condition.

Of course, it is conceivable that the hyperlipemia in patients with especially unstable carbohydrate metabolism is referable to a mobilization of fat, similar to that in diabetic acidosis. In both instances carbohydrate metabolism is impaired, the difference being in degree rather than in kind of dysfunction. One argument against this explanation for the hyperlipemia of diabetics with disturbances of the autonomic nervous system is that a non-diabetic patient (98201), with a basal metabolism of +20 per cent 4 months after thyroidectomy and with the same nervous symptoms as A9255 to 1898 (inclusive), had a serum cholesterol of 532 milligrams per cent and total fatty acids of 44.9 milliequivalents. The hyperlipemia here can not be associated with mobilization of fat, contingent upon impairment of carbohydrate metabolism. There is much temptation to place the onus upon the pituitary, since extracts of this gland both diminish carbohydrate tolerance and augment thyroid activity. One case, indeed, had acromegaly. Moreover, in another acromegalic, without any demonstrable disturbances of carbohydrate tolerance or basal metabolism, serum cholesterol of $302 \mathrm{mgm}$. per cent and total fatty acids of 18.8 m.eq. were discovered. However, in the great majority of cases, it was impossible to implicate the pituitary. In some there were symptoms pointing to affections of the midbrain (Parkinson's syndrome, diabetes insipidus, etc.), and the nature and degree of autonomic instability in many was suggestive of hypothalamic lesions. It is possible that in the acromegalic cases also the hyperlipemia was referable not directly to the tumor of the pituitary and hyperactivity of the acidophilic cells but to encroachment of these tumors upon subjacent structures in the mid-brain. All this must remain mere speculation until the effects of hypophysis and mid-brain on lipoid metabolism are established, either by direct experiment or by studies of more extensive clinical material. An investigation of both diabetic patients and non-diabetic patients with comparable disorders of the autonomic system is now under way. 


\section{CONCLUSIONS}

Serum has been analyzed for lipoids in 79 diabetic patients, 20 males and 59 females, who were not suffering from acidosis or dehydration. Cholesterol was normal in 42, below normal in 9, above normal in 28 .

Cholesterolemia and phospholipoidemia were closely correlated. The correlation with serum fatty acids was less exact, but gross changes in one component were reflected in the others.

Reasons for the low incidence of hyperlipemia in this series are discussed.

The level of serum cholesterol did not appear to be related to the severity of diabetes, the fat in the diet or the degree of arteriosclerosis.

Hypocholesterolemia was associated with extreme malnutrition and hypoproteinemia.

Mild hypercholesterolemia was observed in obese females, but appeared to be related to the pattern of obesity rather than the diet.

Severe hypercholesterolemia was frequently referable to complicating conditions. It was found also in a group of patients who presented instability of the vasomotor reactions and carbohydrate metabolism. The implications of this observation are discussed.

\section{PROTOCOLS}

$A 8513$, male, aged 67, weight $69.5 \mathrm{kgm}$. Diabetes, cirrhosis of liver (hemachromatosis?), moderate hypertension (140 to $170 / 70$ to 80 ), heart failure, ascites, edema of legs, bilateral cataracts. Icteric index 6, no retention of bromsulphalein. In addition, there were some reflex changes and a coarse tremor. He proved extraordinarily resistant to insulin and was seldom entirely free from glycosuria. Serum albumin 3.69 to 4.42 ; globulin 2.36 to 2.81 per cent.

A10517, male, aged 51, weight $113 \mathrm{kgm}$. March 31, 1933, diabetes, slight hypertension $(162 / 84)$, heart failure, chronic emphysema, mild polycythemia. Diabetes quite mild. April 7, general condition improved. January 10, 1934, recurrence of heart failure and acute bronchitis with exaggerated polycythemia. Blood pressure normal. Liver distinctly enlarged throughout.

5496, female, aged 53. Diabetes, malnutrition, hypertension (206 to $176 / 112$ to 100 ), with profuse albuminuria, secondary anemia and moderate edema, admitted to hospital after a mild cerebral vascular accident. The last examination was made a few days before death. Throughout her course in hospital she suffered from a psychosis, probably arteriosclerotic in origin. Serum albumin 2.86 to 2.55 ; globulin 2.52 to 2.70 per cent.

A1231, female, aged 54, weight 44.8 to 53.4 kgm. Diabetes, extremely malnourished, with variable amount of edema, profuse albuminuria, hypertension (220 to $140 / 110$ to 60 ), advanced retinitis, unexplained abdominal pain with vomiting, pulmonary signs suggestive of tuberculosis, but negative sputum. Serum albumin 2.44 to 2.91 ; globulin 2.39 to 2.07 per cent. Blood nonprotein nitrogen 44 to 50 milligrams per cent.

17383 , female, aged 50 , weight $59.4 \mathrm{kgm}$. Diabetes, hypertension (230/110). One kidney removed in 1920; left hemiplegia in 1930.

70975, male, aged 52, weight $81 \mathrm{kgm}$. Diabetes, chronic glomerulonephritis, with albuminuria, without hypertension. Neoplasm of colon. $A 31776$, female aged 72, weight $59 \mathrm{kgm}$. Diabetes, arteriosclerosis with gangrene of toe; after mid-thigh amputation, during attack of generalized cutaneous xanthomatosis. At the time of the examination she had persistent tachycardia, profuse perspiration and glycosuria despite large doses of insulin. There were obvious psychic disturbances.

A9255, female, aged 61. Diabetes mellitus, acromegaly, bronchial asthma. In addition, there was persistent tachycardia, hypertension, extreme vasomotor instability with frequent profuse sweats, and the carbohydrate metabolism was so unstable that glycosuria could never be eliminated entirely without precipitating hypoglycemic shock. The basal metabolism was plus 79 per cent on January 7,1933 . Subtotal thyroidectomy was performed on February 4, 1933, but had a negligible effect upon the symptoms. Subsequent basal metabolisms were: February $17,+27$; February 24, + 32; March 9, + 27; March 31, + 31; April 25, + 45; June 19, + 35; December 13, +32 ; February $6,1935,+40$. In addition, the pituitary gland was treated by $x$-ray without appreciable benefit. Signs of increased intracranial pressure were conspicuously lacking throughout. $A 8380$, female, aged 50, weight $48 \mathrm{kgm}$., wasted. Diabetes, hypertension $(175 / 75)$, persistent tachycardia, extreme vasomotor instability 
with excessive sweating and flushing, chronic urticaria. The carbohydrate metabolism was extremely unstable, making insulin adjustment difficult. It was impossible to obtain a satisfactory basal metabolism because of excessive nervousness; an unsatisfactory determination on October 29 was +36 per cent. There was some symptomatic improvement after iodine therapy.

A30304, female, aged 50, weight $44.5 \mathrm{kgm}$. Diabetes, extremely wasted, with tachycardia, sweating and vasomotor instability, with normal blood pressure. One kidney had been removed in 1932. Glycosuria could not be completely eliminated without precipitating insulin shock. Basal metabolism, May 12 , +11 per cent. Serum albumin 3.98, globulin 1.83 per cent.

A52638, female, aged 32 , weight $47.5 \mathrm{kgm}$. Diabetes; admitted December 6, 1934, with slight bronchopneumonia and signs suggestive of mitral stenosis. After recovery from the acute infection tachycardia persisted, and the basal metabolism was found to be +60 per cent on December 17 . Under iodine it did not fall. Subtotal thyroidectomy was performed on January 15, 1935. On January 29 , the basal metabolism was +16 per cent. Regulation of glycosuria was extremely difficult. There were no signs of hyperthyroidism except tachycardia and increased basal metabolism.

A53920, male, aged 52, weight $92.5 \mathrm{kgm}$. Mild diabetes, hypertension (190 to $168 / 115$ to 98 ), vasomotor instability, excessive perspiration and nervousness. In spite of a basal metabolism of +30 per cent and a greatly restricted diet, he had maintained his weight. The second examination was made after two weeks of iodine therapy when the basal betabolism was +16 per cent.

69743, female, aged 52, weight $42.6 \mathrm{kgm}$. Diabetes, without hypertension, tachycardia or definite signs of hyperthyroidism. She failed to gain weight on a high caloric diet. Glycosuria was regulated with great difficulty. The basal metabolism ranged from +33 to +59 per cent and did not respond to iodine therapy.

$A 32114$, female, aged 70 , weight $48 \mathrm{kgm}$. on admission, increasing to 52.4. Diabetes, senile cataracts and general arteriosclerosis without hypertension. Extremely emaciated and dehydrated from starvation diet on admission. She had a persistent tachycardia, and her carbohydrate metabolism was quite unstable.

34878 , female, aged 70, weight $57.4 \mathrm{kgm}$. Diabetes, general arteriosclerosis without hypertension. Parkinson's disease. (This examination was made at 3 P.M.)

1898, female, aged 57, weight $64.5 \mathrm{kgm}$. Mild diabetes, obesity and hypertension (228/116), during recovery from acute follicular tonsillitis. Developed diabetes insipidus about 8 months later.

$A 9112$, female, aged 56, weight $57 \mathrm{kgm}$. Diabetes, mild pernicious anemia, slight tachycardia, unstable carbohydrate metabolism. Basal metabolism -2 per cent.

$A 7358$, female, aged 13, weight $40 \mathrm{kgm}$. Diabetes, after recovery from acidosis precipitated by an acute exacerbation of a chronic otitis media.

36671 , female, aged 50, weight $62 \mathrm{kgm}$. Mild diabetes, moderate obesity, hypertension (198/ 100), moderate albuminuria, blood nonprotein nitrogen 28 mgm. per cent.

2854, female, aged 53, weight $59.5 \mathrm{kgm}$. Diabetes, moderate obesity, mild hypertension (160/ $90)$, burns of toes.

33222, female, aged 61, weight $58.1 \mathrm{kgm}$. Diabetes, moderate obesity, chronic cholelithiasis and cholecystitis, hypertrophic arthritis of spine.

33580 , female, aged 63 weight $75.9 \mathrm{kgm}$. Diabetes, obesity, cataracts, blood pressure 210 to $155 / 95$ to 85 .

$A 9452$, female, aged 48, weight $65.8 \mathrm{kgm}$. Diabetes, moderate obesity, hypertension (200 to $172 / 120$ to 110 ).

$A 14006$, female, aged 40, weight $76 \mathrm{kgm}$. Diabetes, obesity. Blood pressure 150 to $126 / 100$ to 86.

A30212, female, aged 62, weight $61.1 \mathrm{kgm}$. Diabetes, arteriosclerosis with hypertension (182/ 104) and gangrene of toe.

$A 31035$, female, aged 57 , weight $66.3 \mathrm{kgm}$. Diabetes, obesity, arteriosclerosis, blood pressure $150 / 94$, ulcer of foot.

$A 32422$, female, aged 61. Diabetes, obesity, arteriosclerosis, hypertension (240 to $175 / 110$ to 85), subarachnoid hemorrhage. Lipoid determinations 12 hours before death.

A53097, female, aged 59, weight $57.3 \mathrm{kgm}$. Diabetes, obesity, arteriosclerosis with hypertension $(170 / 90)$. 
29923, female, aged 68. An extremely emaciated diabetic, one day before death from staphylococcus septicemia.

33395, female, aged 55. An extremely emaciated diabetic, one day before death from staphylococcus septicemia. Serum albumin 2.67, globulin 2.02 per cent.

46000, female, aged 65. Diabetes, extreme emaciation, arteriosclerosis with hypertension $(170 / 110)$ and previous amputation of foot. Serum albumin 2.60, globulin 3.39 per cent.

$A 8983$, male, aged 59, weight $62 \mathrm{kgm}$. (with ascites and edema of legs). Diabetes, cirrhosis of liver, emaciated. Serum albumin 2.47, globulin 3.58 per cent.

A9017, female, aged 55. Diabetes, extreme emaciation, arteriosclerosis without hypertension, gangrene of foot, spreading cellulitis, 5 days before death. Serum albumin 3.03, globulin 3.34 per cent.

$A 30909$, male, aged 70, weight $49.7 \mathrm{kgm}$. Diabetes, extreme emaciation, arteriosclerosis without hypertension, multiple ulcers of feet. Serum albumin 3.47, globulin 2.92 per cent.

$A 32215$, male, aged 78 . Diabetes, extremely wasted, during postoperative recovery from appendicitis and peritonitis. Arteriosclerosis with hypertension (178/90), auricular fibrillation and heart failure, edema. Serum albumin 3.12, globulin 1.75 per cent.

$A 32655$, male, aged 71, weight $60.5 \mathrm{kgm}$. Diabetes, extremely wasted, with duodenal ulcer, bleeding ; 8 days before death from acute hemorrhage. Serum albumin 3.43, globulin 1.66 per cent.

A32829, male, aged 57. Diabetes, extremely emaciated, with intestinal obstruction. Died January 15 . Serum albumin 3.73 , globulin 1.28 per cent.

29176, male, aged 46, weight $64.3 \mathrm{kgm}$. Diabetes, normal nutrition; no known complication. 36052 , female, aged 48, weight $81.3 \mathrm{kgm}$. Diabetes, obesity, arteriosclerosis; blood pressure $160 / 100$.

43494, female, aged 60, weight $55.5 \mathrm{kgm}$. Diabetes, mild hypertension (150/95).

45815, female, aged 43, weight $57.7 \mathrm{kgm}$. Diabetes, obesity.
60404 , male, aged 14, weight $42.3 \mathrm{kgm}$. Diabetes, not complicated; slightly obese.

$A 6028$, male, aged 50, weight $81.7 \mathrm{kgm}$. Diabetes, normal nutrition, traumatic ulcer of foot. $A 14670$, female, aged 67, weight $49 \mathrm{kgm}$. Diabetes, arteriosclerosis. Blood pressure 165/80. $A 26960$, male, aged 19, weight $54.2 \mathrm{kgm}$. Diabetes, impetigo.

$A 31733$, female, aged 55 , weight $72.5 \mathrm{kgm}$. Diabetes, obesity, hypertension (180 to $120 / 100$ to 80 ).

$A 32622$, female, aged 75 , weight $50 \mathrm{kgm}$. Diabetes, normal nutrition, arteriosclerosis without hypertension.

$A 33706$, female, aged 25, weight $48.9 \mathrm{kgm}$. Diabetes, during improvement from malnutrition induced by starvation diet.

$A 36853$, male, aged 62 , weight $54.3 \mathrm{kgm}$. Diabetes, ulcer of stomach with pyloric obstruction. During convalescence from gastrectomy. Emaciated, but had taken high caloric diet for some days. Serum albumin 4.41, globulin 2.57 per cent.

$A 42040$, female, aged 24, weight $66 \mathrm{kgm}$. Diabetes.

963, female, aged 54, weight $64.5 \mathrm{kgm}$. Diabetes, obesity, acute cholelithiasis.

5105, male, aged 50, weight $70.5 \mathrm{kgm}$. Diabetes, malnutrition, fractures of femur.

18576, female, aged 54, weight $66 \mathrm{kgm}$. Diabetes, obesity, arteriosclerosis with hypertension (210/110).

29503 , female, aged 56, weight $64.2 \mathrm{kgm}$. Diabetes; admitted with mastoiditis. Later operation for epithelioma of vulva, which resulted in fatal ulceration. The studies were made during the period when nutrition was steadily failing.

34442 , female, aged 49, weight $68.2 \mathrm{kgm}$. Diabetes, obesity, erythema multiforme, arteriosclerosis without hypertension.

36572, female, aged 72, weight $59 \mathrm{kgm}$. Diabetes, renal calculus.

40992, male, aged 64, weight $78.5 \mathrm{kgm}$. Diabetes, moderate obesity, arteriosclerotic heart disease, heart failure, blood pressure 120/68.

15096, female, aged 71. Diabetes, poor nutrition, arteriosclerosis with hypertension (195/105), ulcerated abrasion of toe, mild vasomotor instability evidenced by slight tachycardia and sweat- 
ing, and carbohydrate tolerance so disturbed that sufficient insulin for glycosuria precipitated hypoglycemic shock.

58487 , female, aged 49, weight $81.4 \mathrm{kgm}$. Diabetes, obesity.

61682 , male, aged 57 , weight $52.6 \mathrm{kgm}$. Diabetes, extreme emaciation, arteriosclerosis without hypertension.

79627, female, aged 61, weight $100.2 \mathrm{kgm}$. Diabetes, extreme obesity, arteriosclerosis with heart disease. During recovery from pneumonia and coronary occlusion, when she had been unable to eat and had lost much weight. Moderate edema.

83790 , female, aged 61, weight $67.2 \mathrm{kgm}$. Diabetes, arteriosclerosis with coronary occlusion, femoral thrombophlebitis and edema.

83896 , female, aged 29, weight $67.5 \mathrm{kgm}$. Diabetes mellitus, chronic pelvic inflammatory disease (gonococcal).

85804, female, aged 58, weight $60 \mathrm{kgm}$. Diabetes, arteriosclerosis with hypertension (200/ 100 ), occlusion of popliteal artery, coronary occlusion.

90339, female, aged 41, weight $66.2 \mathrm{kgm}$. Diabetes, obesity, gluteal abscess.

94028, female, aged 58. Diabetes, normal nutrition, arteriosclerosis with slight hypertension $(162 / 96)$, ulcer of foot.

96675, female, aged 52. Diabetes, arteriosclerotic heart disease, coronary occlusion.

$A 7948$, female, aged 71 , weight $59.1 \mathrm{kgm}$. Diabetes, poor nutrition, gastric carcinoma.

$A 8517$, female, aged 56 , weight $59.5 \mathrm{kgm}$. Diabetes, uncomplicated.

$A 9315$, female, aged 67, weight $58.5 \mathrm{kgm}$. Diabetes, trigeminal neuralgia, cataract, arteriosclerosis with hypertension $(152 / 100)$.

$A 15928$, male, aged 61 . Diabetes, poor nutrition, arteriosclerotic heart disease, heart failure, pleural effusion (possibly due to carcinoma).

$A 29051$, female, aged 51 , weight $60.1 \mathrm{kgm}$.

Diabetes, carbuncle of back.

$A 30054$, male, aged 67, weight $86.4 \mathrm{kgm}$. Dia-

betes, obesity, mitral stenosis with heart failure, perforating ulcer of foot.

A30790, female, aged 50, weight $68.2 \mathrm{kgm}$.

Diabetes, obesity, non-toxic goitre.

A30940, female, aged 57. Diabetes, multiple subcutaneous abscesses, emaciation. Serum albumin 2.67 to 3.59 , globulin 3.36 to 3.70 per cent. A32367, female, aged 67. Diabetes, poorly nourished, with arteriosclerosis, coronary disease and gangrene of foot.

A32692, female, aged 66. Diabetes, obesity, gangrene of foot; after mid-thigh amputation. $A 33062$, female, aged 41, weight $67 \mathrm{kgm}$. Diabetes, hyperthyroidism, hypertension (190/110). Basal metabolism +41 per cent.

$A 34635$, female, aged 43, weight $56.7 \mathrm{kgm}$. Acromegaly with mild diabetes; previously treated by $x$-ray of pituitary.

\section{BIBLIOGRAPHY}

1. Aschoff, L., Observations concerning the relationship between cholesterol metabolism and vascular disease. Brit. M. J., 1932, 2, 1131.

2. Bang, I., Utber Lipämie. II. Biochem. Ztschr., 1918, 91, 104.

3. Barach, J. H., Lower fat diet in diabetes. J. A. M. A., 1932, 98, 1265.

4. Benedict, S. R., The estimation of sugar in blood and normal urine. J. Biol. Chem., 1926, 68, 759.

5. Blix, G., Studies on diabetic lipemia. I. Acta med. Scandinav., 1926, 64, 142.

6. Bloor, W. R., Studies on blood fat. II. Fat absorption and the blood lipoids. J. Biol. Chem., 1915, 23, 317.

7. Bloor, W. R., Fat assimilation. J. Biol. Chem., 1916, 24, 447.

8. Bloor, W. R., The distribution of the lipoids ("Fat") in human blood. J. Biol. Chem., 1916, 25, 577.

9. Bloor, W. R., The lipoids ("Fat") of the blood in diabetes. J. Biol. Chem., 1916, 26, 417.

10. Boyd, E. M., A differential lipid analysis of blood plasma in normal young women by micro-oxidative methods. J. Biol. Chem., 1933, 101, 323.

11. Bruckman, F. S., D'Esopo, L. M., and Peters, J. P., The plasma proteins in relation to blood hydration. IV. Malnutrition and the serum proteins. J. Clin. Invest., 1930, 8, 577.

12. Bruger, M., and Poindexter, C. A., Relation of the plasma cholesterol to obesity and to some of the complicating degenerative diseases (diabetes mellitus, essential hypertension, osteo-arthritis and arteriosclerosis). Arch. Int. Med., 1934, 53, 423.

13. Bruger, M., and Somach, I., The diurnal variations of the cholesterol content of the blood. J. Biol. Chem., 1932, 97, 23.

14. Chaikoff, I. L., McGavack, T. H., and Kaplan, A., The blood lipids in the postabsorptive state and after the ingestion' of fat in normal human subjects and in a case of disseminated cutaneous xanthomata. J. Clin. Invest., 1934, 13, 1. 
15. Chamberlain, E. N., The significance of cholesterol in physiology and pathology. A consideration of selected problems. Brit. M. J., 1929, 2, 896.

16. Curtis, A. C., Sheldon, J. M., and Eckstein, H. C., Experimental reproduction of lipemia. Am. J. M. Sc., 1933, 186, 548.

17. Czoniczer, G., and Kolta, E., Der Einfluss der kohlenhydratreichen Diät auf die Toleranz der Zuckerkranken. Med. Klin., 1932, 28, 752.

18. Epstein, E. Z., Cholesterol of the blood plasma in hepatic and biliary diseases. Arch. Int. Med., 1932, 50, 203.

19. Fahrig, C., and Wacker, L., Vergleichende Untersuchungen über den Lipoidkomplex des Blutserums bei essentieller Hypertension, Muskelarbeit, Hunger, Schwangerschaft und Nahrungsaufnahme. Klin. Wchnschr., 1932, 11, 886.

20. Geyelin, H. R., The treatment of diabetes with insulin (after ten years) contrasting the effects of normal and of the older diabetic diets. J. A. M. A., 1935, 104, 1203.

21. Gibbs, C. B. F., Buckner, E., and Bloor, W. R., The cholesterol to cholesterol ester ratio in the plasma of diabetics with advanced arteriosclerosis. New England J. Med., 1933, 209, 384.

22. Glen, Alex, Diabetes mellitus : a broader basis of interpretation. Glasgow M. J., 1934, 122, 194.

23. Graham, G., Clark, A., and Robertson, H. E. W., The high carbohydrate diet in the treatment of diabetes mellitus. Lancet, 1932, 2, 990.

24. Gray, P. A., and Sansum, W. D., The higher carbohydrate diet method in diabetes mellitus. Analysis of 1005 cases. J. A. M. A., 1933, 100, 1580.

25. Grieshaber, H., Uber Beziehungen des Blutcholesterins zum Kohlehydratstoffwechsel mit besonderer Berücksichtigung des Diabetes mellitus. Ztschr. f. klin. Med., 1933-34, 126, 405.

26. Hiller, A., Linder, G. C., Lundsgaard, C., and Van Slyke, D. D., Fat metabolism in nephritis. J. Exper. Med., 1924, 39, 931.

27. Hunt, Hazel M., Cholesterol in blood of diabetics treated at the New England Deaconess Hospital. New England J. Med., 1929, 201, 659.

28. Hurxthal, L. M., Blood cholesterol in thyroid disease. I. Analysis of findings in toxic and in nontoxic goiter before treatment. Arch. Int. Med., 1933, 51, 22.

29. Hurxthal, L. M., Blood cholesterol in thyroid disease. II. Effect of treatment. Arch. Int. Med., 1933, $52,86$.

30. Jamieson, H. C., The high carbohydrate low fat diet for diabetic children. Canad. M. A. J., 1932, 27, 389.

31. Joslin, E. P., An appraisal of the present treatment of diabetes. J. A. M. A., 1931, 97, 595.

32. Kirchgessner, G., Uber das Verhalten des Cholesterinstoff wechsels bei verschiedenen Erkrankungen des Gefässsystems. Klin. Wchnschr., 1934, 13, 976.
33. Knudson, A., Relationship between cholesterol and cholesterol esters in the blood during fat absorption. J. Biol. Chem., 1917, 32, 337.

34. Kulkov, A. E., Veiland, V. I., and Tarnopolskaya, M. E., Biochemical changes in cerebral arteriosclerosis. J. Nevropatologii i Psikhiatrii, Moscow, 1931, 6, 20 (through J. A. M. A., 1932, 99).

35. Laroche, G., Grigaut, A., and Costes, Les variations du rapport des esters du cholestérol au cholestérol total en pathologie. Presse Méd., 1934, 42, 1417.

36. Lawrence, R. D., Diabetes with special reference to high carbohydrate diets. Brit. M. J., 1933, 2, 517.

37. Man, E. B., and Gildea, E. F., A modification of the Stoddard and Drury titrimetric method for the determination of the fatty acids in blood serum. J. Biol. Chem., 1932, 99, 43.

38. Man, E. B., and Peters, J. P., Gravimetric determination of serum cholesterol adapted to the Man and Gildea fatty acid method with a note on the estimation of lipoid phosphorus. J. Biol. Chem., 1933, $101,685$.

39. Man, E. B., and Peters, J. P., Permeability of capillaries to plasma lipoids. J. Clin. Invest., 1933, 12, 1031.

40. Man, E. B., and Peters, J. P., Lipoids of serum in diabetic acidosis. J. Clin. Invest., 1934, 13, 237.

41. McEachern, J. M., and Gilmour, C. R., Studies in cholesterol metabolism. I. Physiological variations in blood cholesterol. Canad. M. A. J., 1932, 26, 30.

42. McGavack, T. H., and Shepardson, H. C., Xanthoma accompanied by hypercholesterolemia, occurring in an otherwise normal individual and in an individual with acromegaly and diabetes. Ann. Int. Med., 1933, 7, 582.

43. Meeker, D. R., and Jobling, J. W., A chemical study of arteriosclerotic lesions in the human aorta. Arch. Path., 1934, 18, 252.

44. Peters, J. P., and Eisenman, A. J., The serum proteins in diseases not primarily affecting the cardiovascular system or kidneys. Am. J. M. Sc., 1933, 186, 808.

45. Petersilie, H., Cholesterol esters as a mechanism of fat metabolism. J. Lab. and Clin. Med., 1934, 20, 144.

46. Rabinowitch, I. M., The cholesterol content of the blood plasma as an index of progress in insulintreated diabetics. Canad. M. A. J., 1927, 17, 171.

47. Rabinowitch, I. M., The cholesterol content of blood plasma in diabetes mellitus. A statistical study based on 2000 observations in 385 cases. Arch. Int. Med., 1929, 43, 363.

48. Rabinowitch, I. M., Experiences with a high carbohydrate low-calorie diet for the treatment of diabetes mellitus. Canad. M. A. J., 1930, 23, 489.

49. Rabinowitch, I. M., Observations on the significance of the cholesterol content of the blood plasma in diabetes mellitus. Canad. M. A. J., 1933, 28, 162. 50. Rabinowitch, I. M., and Beard, M., The colloidal os- 
motic pressure of the blood. Arch. Int. Med., 1930, 46, 752.

51. Rony, H. R., and Levy, A. J., Studies on fat metabolism. I. Fat tolerance in obesity. A preliminary study. J. Lab. and Clin. Med., 1929, 15, 221.

52. Rosenberg, M., Beitrag zur kohlenhydratreichen, fettarmen Diät bei Diabetes. Deutsche med. Wchnschr., 1933, 59, 320.

53. Rosenthal, S. R., Studies in atherosclerosis : chemical, experimental and morphologic. I, II, III and IV. Rôles of cholesterol metabolism, blood pressure and structure of the aorta: the fat angle of the aorta (F. A. A.) and the infiltration-expression theory of lipoid deposit. Arch. Path., 1934, 18, 473 and 660 .

V. Possible dangers of iodine therapy in atherosclerosis of aorta seen from an experimental standpoint. Ibid., 1934, 18, 827.

54. Somogyi, M., A method for the preparation of blood filtrates for the determination of sugar. J. Biol. Chem., 1930, 86, 655.
55. Thannhauser, S. J., and Schaber, Hans, Uber die Beziehungen des Gleichgewichtes Cholesterin und Cholesterinester im Blut und Serum für Leberfunktion. Klin. Wchnschr., 1926, 5, 252.

56. Turner, K. B., Studies on the prevention of cholesterol atherosclerosis in rabbits. I. The effects of whole thyroid and of potassium iodide. J. Exper. Med., 1933, 58, 115.

57. Turner, K. B., and Khayat, G. B., Studies on the prevention of cholesterol atherosclerosis in rabbits. II. The influence of thyroidectomy upon the protective action of potassium iodide. J. Exper. Med., 1933, 58, 127.

58. Wacker, L., and Fahrig, C., Uber die mineralischen und lipoiden Bestandteile des Blutserums bei der essentiellen Hypertension im Vergleich zu den physiologischen Verhältnissen. Klin. Wchnschr., 1932, 11, 762.

59. White, P., and Hunt, H., Cholesterol of the blood of diabetic children. New England J. Med., 1930, 202, 607. 